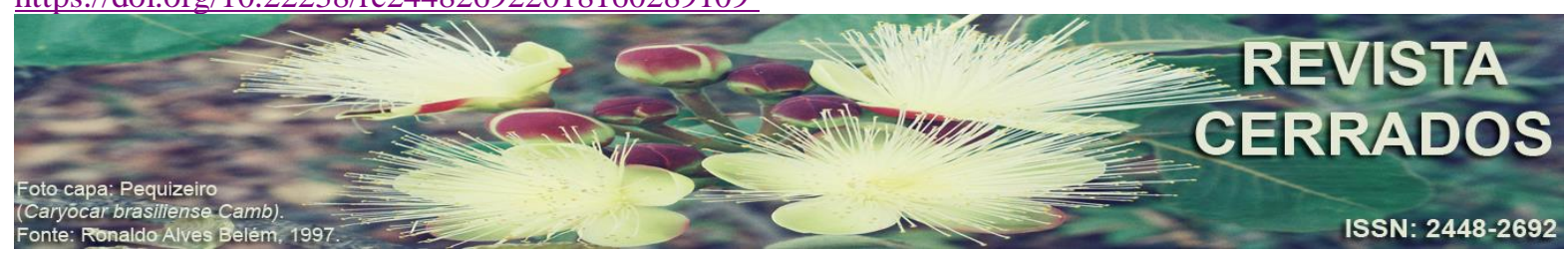

\title{
A DINÂMICA AGROINDUSTRIAL NA MICRORREGIÃO DE ANÁPOLIS
}

\section{THE AGROINDUSTRIAL DYNAMICS IN THE ANÁPOLIS MICROREGION}

\section{EL AGROINDUSTRIAL DYNAMICS EN LOS ANÁPOLIS MICROREGION}

\author{
Idelmar da Silva Ribeiro \\ Universidade Estadual de Goiás - UEG \\ E-mail: <idelmarribeiro5@gmail.com>. \\ Janes Socorro da Luz \\ Universidade Estadual de Goiás - UEG \\ E-mail: <jnsluz@hotmail.com>.

\section{Divina Aparecida Leonel Lunas \\ Universidade Estadual de Goiás - UEG \\ E-mail: <divalunas@gmail.com>.}

\begin{abstract}
RESUMO
O agronegócio é sabidamente a principal atividade econômica do estado de Goiás, assim, a industrialização, baseada nesse segmento, configurou-se como a primeira opção do Estado como forma de desenvolvimento e diminuição da dependência econômica em commodities. Nessa perspectiva, o presente estudo tem por objetivo analisar a dinâmica agroindustrial na microrregião de Anápolis, composta por 20 municípios, que em sua maioria possuem economia fortemente vinculada à agropecuária. Para tanto, foram estudados dados econômicos e demográficos disponibilizados por órgãos públicos. Sendo que, verifica-se a importância do agronegócio para a região, e a necessidade de se desenvolver a atividade agroindustrial, principalmente relacionada à pequena propriedade rural, como forma de incentivar o desenvolvimento dos municípios, e a fixação da população em seus municípios de origem.
\end{abstract}

Palavras-chave: Agroindústria. Distrito Agroindustrial. Agronegócio.

Licenciada sob Creative Commons

(cc) BY-WE-WD
Revista Cerrados, Departamento de Geociências e Programa de Pós-Graduação em Geografia (UNIMONTES) 
RIBEIRO, I. S.; LUZ, J. S.; LUNAS, D. A. L.

A dinâmica agroindústrial na microrregião de Anápolis

\begin{abstract}
Agribusiness is known to be the main economic activity in the state of Goiás, and industrialization, based on this segment, has become the first option of the state as a form of development and decrease of economic dependence on commodities. In this perspective, the present study has the objective of analyzing the agroindustrial dynamics in the Anápolis microregion, composed of 20 municipalities, most of which have an economy strongly linked to farming. For that, economic and demographic data provided by public agencies were studied. The importance of agribusiness for the region and the need to develop agroindustrial activity, mainly related to small rural property, as a way of encouraging the development of municipalities, and the establishment of the population in its municipalities of origin.
\end{abstract}

Key Words: Agroindustry. Agroindustrial District. Agribusiness.

\title{
RESUMEN
}

El agronegocio es sabidamente la principal actividad económica del estado de Goiás y la industrialización, basada en ese segmento, se configuró como la primera opción del Estado como forma de desarrollo y disminución de la dependencia económica en commodities. En esta perspectiva, el presente estudio tiene por objetivo analizar la dinámica agroindustrial en la microrregión de Anápolis, compuesta por 20 municipios, que en su mayoría poseen una economía fuertemente vinculada a la agropecuaria. Para ello se estudiaron datos económicos y demográficos disponibles por organismos públicos. Siendo que, se verifica la importancia del agronegocio para la región, y la necesidad de desarrollar la actividad agroindustrial, principalmente relacionada a la pequeña propiedad rural, como forma de incentivar el desarrollo de los municipios, y la fijación de la población en sus municipios de origen.

Palabras clave: Agroindustria. Distrito Agroindustrial. Agronegocio.

\section{INTRODUÇÃO}

O presente estudo apresenta como foco o crescimento agroindustrial da microrregião de Anápolis que tem grande importância econômica, pois concentra 13\% do Produto Interno Bruto (PIB) do estado de Goiás, perdendo apenas para a microrregião de Goiânia. Embora, a capital apresente uma elevada concentração do PIB no município de Anápolis, cidade polo com destacada atividade agroindustrial, seguida dos Municípios de Inhumas, Itaberaí e Jaraguá, que exercem a função de subpolos. Sendo que, os demais municípios da microrregião apontam, de forma geral, economia basicamente agropecuária, com base na agricultura familiar e pouca agregação de valor, o que reflete na oferta de empregos para a população economicamente ativa desses municípios. Nessa dinâmica, a microrregião segue uma tendência de concentração da população no município polo e dos 
RIBEIRO, I. S.; LUZ, J. S.; LUNAS, D. A. L.

A dinâmica agroindústrial na microrregião de Anápolis

subpolos, que vêm crescendo seu contingente populacional em detrimento dos demais municípios da microrregião, sendo necessárias ações por parte do poder público no sentido de reverter essa situação. Isto é, é preciso proporcionar meios para que esses municípios menores possam ter um crescimento sustentado, que contribua para a fixação dos jovens em seu município de origem.

\section{A FORMAÇÃO DOS COMPLEXOS AGROINDUSTRIAIS NA MICRORREGIÃO DE ANÁPOLIS}

O estado de Goiás é subdividido em 18 microrregiões geográficas, sendo elas: Anápolis, Anicuns, Aragarças, Catalão, Ceres, Chapada dos Veadeiros, Entorno de Brasília, Goiânia, Iporá, Meia Ponte, Pires do Rio, Porangatu, Quirinópolis, Rio Vermelho, São Miguel do Araguaia, Sudoeste de Goiás, Vale do Rio dos Bois e Vão do Paranã (figura 1).

Figura 1- Microrregiões do estado de Goiás



Fonte: Os autores (2017).

Revista Cerrados, Montes Claros/MG, v. 16, n. 2, p. 89-109, jul./dez.-2018. 
RIBEIRO, I. S.; LUZ, J. S.; LUNAS, D. A. L.

A dinâmica agroindústrial na microrregião de Anápolis

A microrregião de Anápolis insere-se na mesorregião Centro Goiano (Quadro 1), tendo como principal polo a Cidade de Anápolis, que em função da sua localização privilegiada, exerceu grande influência no desenvolvimento econômico do estado desde fins do século XIX, servindo como entreposto comercial para as mercadorias que vinham do sul e sudeste do país.

Quadro 1 - As mesorregiões de Goiás e suas microrregiões

\begin{tabular}{|c|c|}
\hline $\begin{array}{l}\text { MESORREGIÕES DO ESTADO DE } \\
\text { GOIÁS }\end{array}$ & $\begin{array}{c}\text { MICRORREGIÕES PERTENCENTES A CADA } \\
\text { MESORREGIÃO }\end{array}$ \\
\hline Norte de Goiás & $\begin{array}{l}\text { - Chapada dos Veadeiros } \\
\text { - Porangatu }\end{array}$ \\
\hline Noroeste de Goiás & $\begin{array}{l}\text { - Aragarças } \\
\text { - Rio Vermelho } \\
\text { - São Miguel do Araguaia }\end{array}$ \\
\hline Leste de Goiás & $\begin{array}{l}\text { - Entorno do Distrito Federal } \\
\text { - Vão do Paranã }\end{array}$ \\
\hline Centro Goiano & $\begin{array}{l}\text { - Anápolis } \\
\text { - Anicuns } \\
\text { - Ceres } \\
\text { - Goiânia } \\
\text { - Iporá }\end{array}$ \\
\hline Sul Goiano & $\begin{array}{l}\text { - Catalão } \\
\text { - Meia Ponte } \\
\text { - Pires do rio } \\
\text { - Quirinópolis } \\
\text { - Sudoeste de Goiás } \\
\text { - Vale do Rio dos Bois }\end{array}$ \\
\hline
\end{tabular}

Fonte: Luz, 2009. Adaptado pelos autores.

Conforme destaca Luz (2009), os estados do Centro-Oeste do país desenvolveram suas estruturas econômicas ligadas principalmente à pecuária extensiva, que permitiam alguns elos econômicos com São Paulo e Minas Gerais. Porém, as primeiras ações efetivas para desenvolver o território Goiano e torná-lo atrativo foram as frentes pioneiras que abriram caminho para a colonização do território e "com a consequente interiorização do povoamento anexaram novas áreas produtivas ao mercado nacional” (LUZ, 2009, p. 107).

Nesse movimento, a região de Anápolis se destacou por apresentar áreas propícias ao cultivo do café (Luz, 2009), devido ao solo fértil, o que atraiu grande contingente populacional, principalmente para a região de Anápolis. Nessa dinâmica, Silva (1997, p. 34) destaca que "paralela à criação de gado inicia-se em Goiás nos anos 20, a produção de café voltada para a exportação, sendo o município de Anápolis o maior produtor do Estado". Fato que impulsionava o crescimento econômico da região, principalmente do município de Anápolis que despontava como importante entreposto comercial de grãos. 
RIBEIRO, I. S.; LUZ, J. S.; LUNAS, D. A. L.

A dinâmica agroindústrial na microrregião de Anápolis

Luz (2009) destaca a importância da chegada da ferrovia em Anápolis, ou seja, a estrada de ferro Goyas (1935) como um dos fatores que permitiram o desenvolvimento da região, principalmente da agroindústria com a instalação das primeiras beneficiadoras de produtos agrícolas. Fato comprovado com a implantação da Colônia Agrícola Nacional de Goiás no município de Ceres e da Delegacia Nacional do Café em Anápolis, que trouxe consigo uma usina de despolpeamento, beneficiamento e comercialização do café (SILVA, 1997).

O desenvolvimento gerado com a chegada da estrada de ferro Goyas (1935), juntamente com a construção de Goiânia, contribuíram para a instalação de novas empresas, movimentando o comércio e abrindo a possibilidade de novos negócios, principalmente relacionados à produção agropecuária. Já que, foi nesse período que se iniciaram a instalação de grandes armazéns e cerealistas no município, que tinham por função comercializar e escoar a produção de grãos da região. Tal desenvolvimento, influenciou sobremaneira os municípios vizinhos que tinham como principal atividade econômica a produção agropecuária e direcionavam seus produtos para a cidade de Anápolis, que tinha por função o escoamento dessa produção.

Atualmente, a microrregião de Anápolis conta com 20 municípios: Anápolis, Araçu, Brazabrantes, Campo Limpo de Goiás, Caturaí, Damolândia, Heitoraí, Inhumas, Itaberaí, Itaguari, Itaguaru, Itauçu, Jaraguá, Jesúpolis, Nova Veneza, Ouro Verde de Goiás, Petrolina de Goiás, Santa Rosa de Goiás, São Francisco de Goiás, taquaral de Goiás (Figura 2).

A microrregião de Anápolis possui 540.220 habitantes, segundo informações censitárias de 2010 do Instituto Brasileiro de Geografia e Estatística (IBGE/Censo Demográfico, 2010) com população estimada de 594.914 habitantes para 2016 (IBGE/Cidades, 2017), registrando em 2014, um Produto Interno Bruto de R\$ 1.631.917.700,00 (IBGE/Cidades, 2014), cuja geração possui significativa contribuição das atividades ligadas ao agronegócio (11,3\%, do PIB, segundo dados do IMB,2014). 
RIBEIRO, I. S.; LUZ, J. S.; LUNAS, D. A. L.

A dinâmica agroindústrial na microrregião de Anápolis

Figura 2: Microrregião de Anápolis e Principais Rodovias

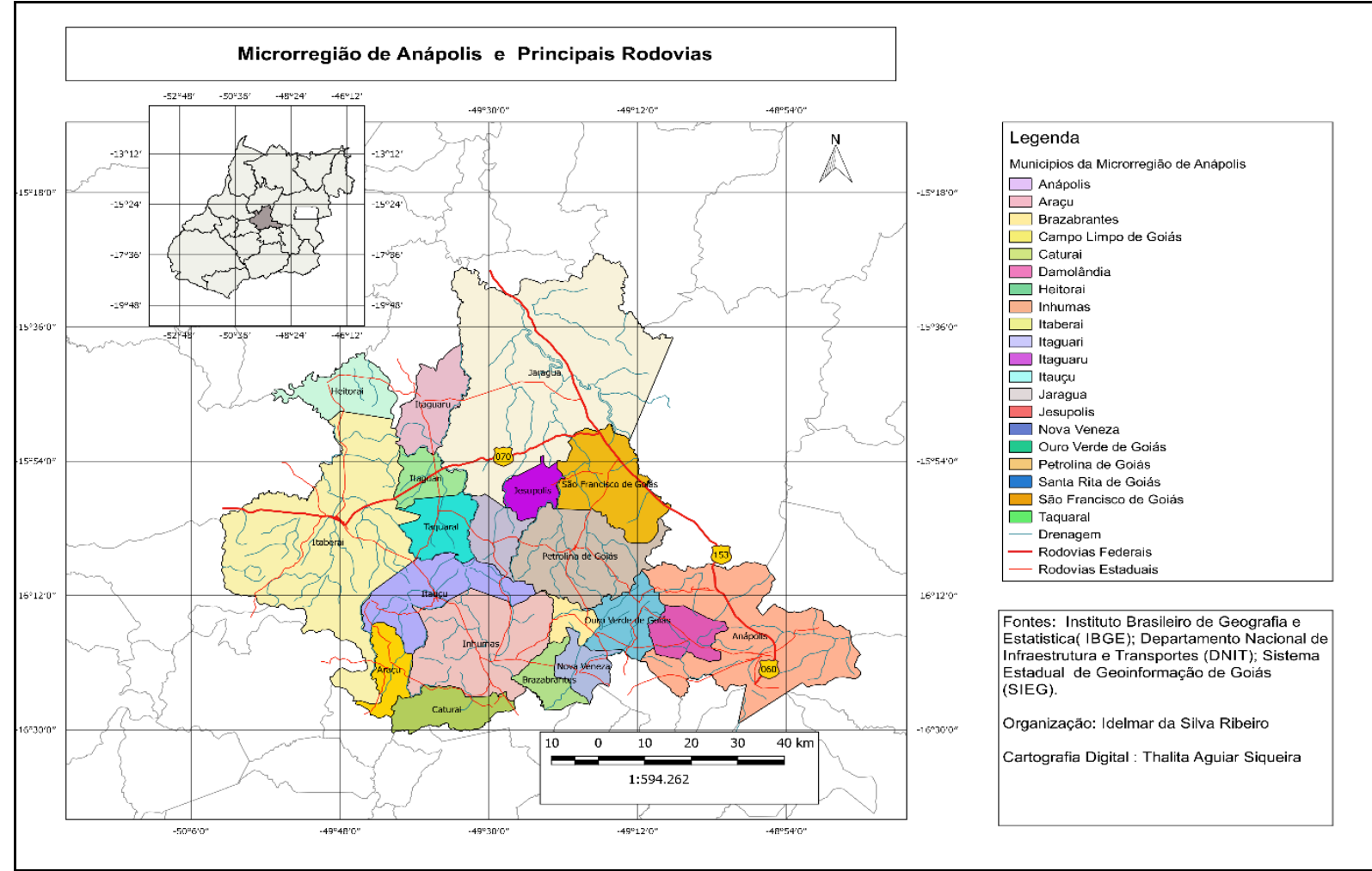

Fonte: Os autores (2017).

Conforme dados do Instituto Mauro Borges (IMB, 2014), com relação à concentração do PIB nas microrregiões de Goiás, entre 2002 e 2011, a microrregião de Anápolis concentrava $13 \%$ do PIB estadual, sendo o $2^{\circ}$ maior do Estado. Ou seja, perdendo apenas para a microrregião de Goiânia, em primeiro lugar, com 36,61\% de participação no PIB do Estado, e sendo seguida pela Região do Sudoeste Goiano com 10,94\% (IMB, 2014). Assim, grande parte do PIB do Estado e da microrregião decorre do desenvolvimento dos sistemas agroindustriais, pois segundo dados da Fundação Getúlio Vargas (FGV EESP, 2014), o PIB do Agronegócio em Goiás, corresponde a 28\% do PIB total (somando-se à fabricação de insumos, à agropecuária e à agroindústria).

Dessa forma, para que possamos compreender a dinâmica agroindustrial na microrregião de Anápolis, e sua importância para o desenvolvimento da região, faz-se necessário compreender o processo de formação dos complexos agroindustriais e sua distribuição entre as meso e microrregiões do Estado. 
RIBEIRO, I. S.; LUZ, J. S.; LUNAS, D. A. L.

A dinâmica agroindústrial na microrregião de Anápolis

\section{A FORMAÇÃO DOS COMPLEXOS AGROINDUSTRIAIS EM GOIÁS E NO BRASIL}

Alguns conceitos fundamentais serão elencados nesse item. O primeiro refere-se ao termo agronegócio ou agribusiness que conforme a Associação Brasileira do Agronegócio da Região de Ribeirão Preto (ABAGRP), surgiu nos Estados Unidos (EUA), em 1957, e define-se como:

Agronegócio é a soma das operações de produção e distribuição de suprimentos agrícolas, das operações de produção nas unidades agrícolas, do armazenamento, processamento e comercialização dos produtos agrícolas e itens produzidos a partir deles. E envolve desde a pesquisa científica até a comercialização de alimentos, fibras e energia (ABAGRP, sd).

Nesse sentido, o conceito de agronegócio pode ser entendido como um conceito amplo que envolve toda uma cadeia que vai desde a produção agropecuária em si até à comercialização do produto final, tendo como parte importante deste processo os Complexos Agroindustriais, que são assim definidos por Müller (1989):

Entenda-se por Complexo Agroindustrial o conjunto de relações entre
indústria e agricultura na fase em que esta mantém intensas conexões para
trás, com a indústria para a agricultura e para frente, com as agroindústrias e outras
unidades de intermediação que exercem impactos na dinâmica
agrária. O Complexo Agroindustrial é uma forma de unificação das relações
entre os grandes departamentos econômicos com os ciclos e as esferas de
produção, distribuição e consumo, relações estas associadas às atividades
agrárias. (MÜLLER, 1989, p.4).

Siki (1997, p.135), ao complementar essa definição sobre os sistemas agroindustriais no cerrado, afirma que: “A agroindústria, seja a montante como as indústrias de fertilizantes e calcários, seja a jusante como as processadoras de matérias primas agrícolas, e um ramo privilegiado de inversões de indústrias líderes como a Sadia, a Ceval e a Perdigão".

Dessa forma, o complexo agroindustrial agrega valor à produção agropecuária contribuindo para o desenvolvimento econômico das regiões produtoras. Inclusive, no estado de Goiás o processo de industrialização, passa primeiramente pela implantação dos distritos industriais (Castro, 2014), que inicialmente tinham por objetivo atrair e consolidar as indústrias ligadas ao agronegócio (Cerealistas, esmagadoras de café, indústrias alimentícias, dentre outras). 
RIBEIRO, I. S.; LUZ, J. S.; LUNAS, D. A. L.

A dinâmica agroindústrial na microrregião de Anápolis

Para que possamos entender a dinâmica desse processo, é preciso retornarmos um pouco e fazermos uma breve análise da transição do complexo rural para o agroindustrial no Brasil e em Goiás, para a partir de então compreendermos o processo de industrialização na região de Anápolis. De acordo com Paranaíba (2012), houve no país uma transição do complexo rural para os complexos agroindustriais, decorrente de um processo histórico de modificação na dinâmica da agricultura brasileira.

Nesse sentido, o complexo rural exportador, na época do Brasil colônia, tinha como características marcantes a monocultura voltada unicamente ao mercado externo, com pouca tecnificação e especialização do trabalho. Mas, a partir de 1850, esse complexo entra em grave crise, principalmente em função da proibição do tráfico negreiro e da promulgação da Lei de Terras. Episódios que marcam o início do processo de passagem do trabalho escravo para o trabalho livre, promovendo uma nova dinâmica no campo, com surgimento de um proletariado rural, e a consequente divisão e especialização do trabalho. Assim, esses acontecimentos permitiram o surgimento de um novo sistema agrícola, baseado na acumulação de capital (PARANAÍBA, 2012).

Nesse contexto, merece destaque a produção de café em São Paulo, que permitiu a formação de uma elite altamente capitalizada, que passou a investir no beneficiamento do café e em outros ramos agroindustriais. Paralelamente a esse sistema altamente capitalizado, houve a formação de alguns pequenos produtores de alimentos e de pequenas indústrias rurais (principalmente alambiques) que tinham como função o abastecimento das cidades e vilas que se formavam. Tais movimentos, segundo Paranaíba (2012), formaram o embrião do processo de agroindustrialização no país.

O crescimento e a ascensão do complexo cafeeiro permitiram um vigoroso crescimento das cidades, consequentemente esse crescimento favoreceu a modernização da base técnica da produção agrícola, principalmente a partir da importação de máquinas e insumos, no período pós-guerra. Processo que permitiu, conforme destaca Graziano da Silva (1998), uma integração da agricultura com o capital industrial, passando a indústria a figurar como o principal demandante de produtos agrícolas em larga escala, o que consequentemente estimulou toda uma cadeia a jusante (máquinas, fertilizantes, combustíveis e outros), também sob o domínio do capital industrial.

Dessa forma, com a vinda das primeiras indústrias de insumos, fertilizantes e máquinas agrícolas para o Brasil, principalmente no fim da era Vargas, inicia-se uma nova 
RIBEIRO, I. S.; LUZ, J. S.; LUNAS, D. A. L.

A dinâmica agroindústrial na microrregião de Anápolis

fase, classificada por Delgado (1985, p. 34) como "A industrialização da agricultura", ou industrialização do campo que "caracteriza-se, fundamentalmente, pela implantação, no Brasil, de um setor industrial produtor de bens para a agricultura".

A partir desse momento, a indústria passa a ditar os rumos da produção agropecuária, seja com relação à quantidade produzida, seja com relação à qualidade e variedade da produção, criando um movimento de integração e subordinação da agricultura em relação à indústria, o que também leva a uma grande dependência com o capital financeiro (PARANAÍBA, 2012).

Esse período também se caracterizou por vultuosos investimentos governamentais no setor agrícola e agroindustrial, no sentido de fomentar a modernização da agricultura e a instalação de um parque industrial, com destaque para os investimentos na região centrooeste. Isso ocorreu por meio dos Planos de Desenvolvimento, com foco na agricultura, a exemplo do Plano de Desenvolvimento do Cerrado (POLOCENTRO), que estimulava o capitalismo no campo.

Com o processo de modernização do campo, a dinâmica da agricultura na região Centro-Oeste apresenta profundas transformações, criando um novo padrão produtivo, em função dos grandes investimentos de capital. Assim, essa dinâmica reflete-se fortemente no estado de Goiás, que passa a figurar como um dos principais produtores agropecuários do país (Figura 3).

Figura 3 - Goiás no ranking nacional de produtos agropecuários (2014)

\begin{tabular}{|c|c|c|c|c|}
\hline \multicolumn{2}{|c|}{$\begin{array}{l}\text { Produtos agropecuários } \\
\text { lideres no ranking nacional }\end{array}$} & \multicolumn{2}{|c|}{$\begin{array}{r}\text { Posiçâano no } \\
\text { Ranking Nacional }\end{array}$} & \multirow{2}{*}{ 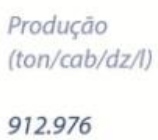 } \\
\hline 10 & \multirow{2}{*}{ Sorgo } & Tomate & $2^{\circ}$ & \\
\hline 10 & & Sorgo & $1^{\circ}$ & 898.123 \\
\hline $2^{\circ}$ & \multirow[t]{2}{*}{ Tomate, melancia, cana-de-açúcar, alho } & Girassol & $3^{\circ}$ & 11.133 \\
\hline & & Melancia & $2^{\circ}$ & 246.950 \\
\hline $3^{\circ}$ & Girassol & Cana-de-açúcar & $2^{\circ}$ & 70.412 .725 \\
\hline $4^{\circ}$ & \multirow{2}{*}{ Algodão, soja, milho, bovino, leite, grãos } & Algodão & $4^{\circ}$ & 131.995 \\
\hline & & Feijão & $5^{\circ}$ & 289.463 \\
\hline $5^{\circ}$ & Feijāo & Soja & $4^{\circ}$ & 8.606 .210 \\
\hline $6^{\circ}$ & \multirow{2}{*}{ Batata inglesa, trigo } & Milho & $4^{\circ}$ & 9.512 .503 \\
\hline $0^{2}$ & & Batata Inglesa & $6^{\circ}$ & 243.470 \\
\hline 70 & \multirow{2}{*}{ Suíno, aves } & Trigo & $6^{\circ}$ & 43.857 \\
\hline \multirow{6}{*}{$9^{\circ}$} & & Alho & $2^{\circ}$ & 34.741 \\
\hline & \multirow{5}{*}{ Ovos } & Bovino & $4^{\circ}$ & 21.887 .720 \\
\hline & & $\begin{array}{r}\text { Suino } \\
\text { Aves }\end{array}$ & $\begin{array}{l}7^{\circ} \\
7^{\circ}\end{array}$ & 2.033 .914 \\
\hline & & Leite & $4^{\circ}$ & $\begin{array}{l}64.174 .315 \\
3.518 .057\end{array}$ \\
\hline & & Ovos & 90 & 187.966 \\
\hline & & Grãos & $4^{\circ}$ & 19.577 .125 \\
\hline
\end{tabular}

Fonte: Instituto Mauro Borges (IMB), 2016, p. 17. 
RIBEIRO, I. S.; LUZ, J. S.; LUNAS, D. A. L.

A dinâmica agroindústrial na microrregião de Anápolis

Castro e Fonseca (1995) comentam que o processo de ocupação agroindustrial no estado tem seu início com a expansão da fronteira agrícola a partir da década de 1970 que, aliada a tecnificação do campo, permitiu um incremento na produtividade e, consequentemente, o início das atividades de beneficiamento de grãos no estado. Posteriormente, entre a década de 1970 e 1980, houve a entrada de grandes grupos empresariais, principalmente em função da adaptação da soja no cerrado, o que permitiu deslocamento de grandes conglomerados agroindustriais para a região a partir da segunda metade da década de 1980.

Contudo, Paranaíba (2012) ressalta que em Goiás o processo de agroindustrialização ocorreu de forma distinta dos demais estados do Centro-Oeste, pois a modernização da agricultura, somado ao grande crescimento demográfico permitiram um rápido afloramento da dinâmica industrial no estado a partir da década de 1970, em função do crescimento de culturas como a do arroz que demandava operações de beneficiamento. Dessa forma, tais estruturas serviram de apoio para a agroindustrialização, com destaque para a cidade de Anápolis que nesse período já se destacava como grande centro comercial, com um grande número cerealistas em operação. Posteriormente, destaca-se a consolidação do complexo de grãos-carnes principalmente na microrregião sudoeste de Goiás (década de 1980), que se intensifica a partir da década de 1990, com a introdução da cadeia de aves e suínos integrada à produção de rações e farelos derivados de grãos.

Nessa linha de pensamento, Shiki (1997) destaca que a intensificação da agricultura nas regiões de cerrado marca uma nova dinâmica no desenvolvimento da região, com uma rápida integração com o sistema agroalimentar mundial, dominado por grandes corporações. Ainda de acordo com Paranaíba (2012), a instalação de empresas agroindustriais em Goiás, especialmente nas mesorregiões, Centro e Sul de Goiás (Quadro 1), teve como objetivo assegurar o acesso às fontes de matérias-primas (soja) que se expandiam nessas regiões. Inclusive, tal ocupação, se caracterizava por uma disputa entre multinacionais que buscam ocupação estratégica, através de plantas agroindustriais.

Nesse sentido, o desenvolvimento Agroindustrial no estado ocorreu de forma bastante desigual, com destaque para as mesorregiões Centro e Sul de Goiás, regiões estas que se destacavam na produção agropecuária, muito em função de suas colonizações por fazendeiros vindos da região Sul e Sudeste do País, que trouxeram consigo a experiência de 
RIBEIRO, I. S.; LUZ, J. S.; LUNAS, D. A. L.

A dinâmica agroindústrial na microrregião de Anápolis

trabalho, tanto na agricultura e pecuária, quanto na criação de suínos, frangos e aves (ramos que ganham cada vez mais destaque no estado).

Tal fato, pode ser evidenciado ao se analisar os dados da Figura 4, ao verificar-se que as Mesorregiões Centro e Sul Goiano, tomadas em conjunto, detêm 85,43\% (1202 empresas de um total 1407) das empresas selecionadas para representar o setor agroindustrial $^{1}$. Nesse sentido, pode-se observar que a mesorregião Centro Goiano destaca-se com relação à fabricação de Produtos de Carne, laticínios, calçados e artefatos de couro, e a mesorregião Sul Goiano destaca-se na fabricação de açúcar e álcool.

Figura 4 - Estado de Goiás: Estabelecimentos Agroindustriais por Mesorregião (2014)

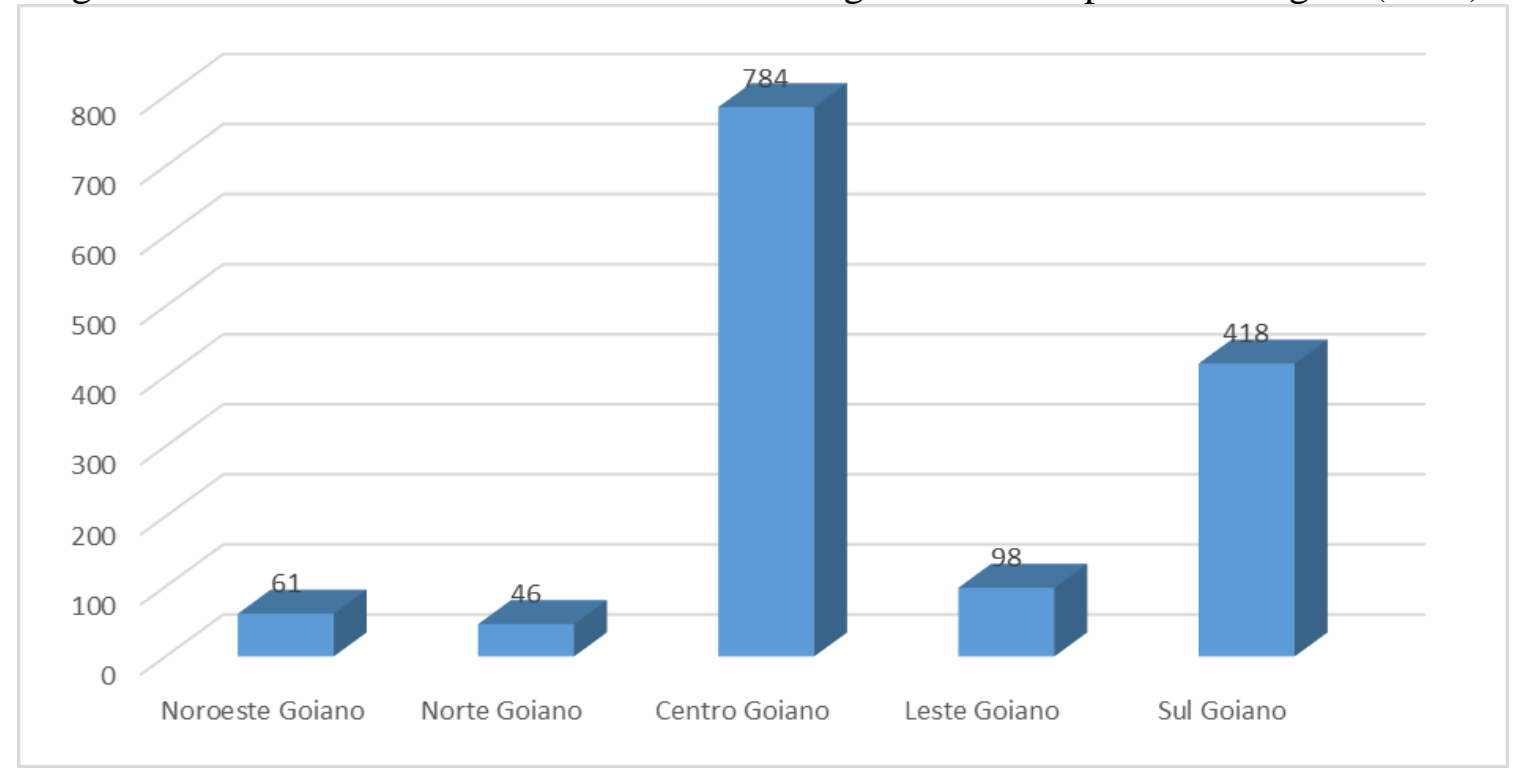

FONTE: Ministério do trabalho e Emprego (MTE/ RAIS 2015), dados organizados pelos Autores.

\footnotetext{
${ }^{1}$ Conforme Paranaíba (2012) e adaptado pelo autor, foram selecionados 29 ramos de atividade (Cadastro Nacional de Atividade econômica - CNAE), sendo eles: Abate de Reses, Exceto Suínos; Abate de Suínos, Aves e Outros Pequenos Animais; Fabricação de Produtos de Carne; Preservação do Pescado e Fabricação de Produtos do Pescado; Fabricação de Conservas de Frutas; Fabricação de Conservas de Legumes e Outros Vegetais; Fabricação de Sucos de Frutas, Hortaliças e Legumes; Fabricação de óleos Vegetais em Bruto, Exceto óleo de Milho; Fabricação de óleos Vegetais Refinados, Exceto óleo de Milho; Preparação do Leite; Fabricação de Laticínios; Beneficiamento de Arroz e Fabricação de Produtos do Arroz; Moagem de Trigo e Fabricação de Derivados; Fabricação de Farinha de Mandioca e Derivados; Fabricação de Farinha de Milho e Derivados, Exceto óleos de Milho; Fabricação de Alimentos para Animais; Moagem e Fabricação de Produtos de Origem Vegetal não Especificados Anteriormente; Fabricação de Açúcar em Bruto; Torrefação e Moagem de Café; Fabricação de Aguardentes e Outras Bebidas Destiladas; Fabricação de Malte, Cervejas e Chopes; Fabricação de Produtos do Fumo; Curtimento e Outras Preparações de Couro; Fabricação de Artefatos de Couro não Especificados Anteriormente; Fabricação de Calçados de Couro; Fabricação de álcool; Fabricação de Adubos e Fertilizantes; Fabricação de Medicamentos para Uso Veterinário; Fabricação de Máquinas e Equipamentos para a Agricultura e Pecuária, Exceto para Irrigação; com o objetivo de facilitar a melhor visualização das atividades agroindustriais presentes em Goiás.
} 
RIBEIRO, I. S.; LUZ, J. S.; LUNAS, D. A. L.

A dinâmica agroindústrial na microrregião de Anápolis

\section{O DESENVOLVIMENTO AGROINDUSTRIAL NA MICRORREGIÃO DE ANÁPOLIS}

Conforme dito anteriormente, a microrregião de Anápolis conta com 20 municípios, tendo em Anápolis o principal município da microrregião, de acordo com Luz (2009), além de Anápolis os municípios de Jaraguá e Itaberaí, destacam-se "pela dinâmica econômica e demográfica que apresentam e constituem polos em seus respectivos subespaços" (Luz, 2009, p. 194). Dessa forma, segundo a mesma autora, os três municípios formam uma triangulação que abarca a maioria das cidades da microrregião (Figura 5).

Figura 5 - Microrregião de Anápolis (GO): Municípios, Área efetiva de influência da cidade



Fonte: Luz, 2009. Adaptado pelos Autores.

Ainda, conforme Luz (2009), o município de Inhumas também se destaca no contexto da microrregião, exercendo influência sobre um subespaço formado pelos municípios que integram a Rede Integrada de Desenvolvimento de Goiânia (RIDG), sendo eles: Inhumas, Brazabrantes, Damolândia, Nova Veneza e Caturaí. Dessa forma, para efeito de análise, serão considerados individualmente os dados da cidade polo (Anápolis) e dos subpolos: Itaberaí, Inhumas e Jaraguá (Luz, 2009). Já os demais municípios, serão 
RIBEIRO, I. S.; LUZ, J. S.; LUNAS, D. A. L.

A dinâmica agroindústrial na microrregião de Anápolis

considerados em conjunto, como forma de melhor visualizar a distribuição da atividade agroindustrial dentro da microrregião.

De acordo com o estudo do IMB (IMB, 2014), no período entre 2002 e 2011, a participação da microrregião de Anápolis, no total do PIB estadual, passou de 8,0\% em 2002 para 13,0\% em 2011. Mas em 2014 essa proporção caiu muito, para 9,88\%, em função do maior crescimento apresentado por outras microrregiões. No gráfico 2, é apresentada a distribuição do PIB na microrregião de Anápolis, podendo-se destacar o fato de que o município de Anápolis em 2014 detinha sozinho 77,91\% do PIB da microrregião.

Figura 6 - Produto Interno Bruto dos Municípios da microrregião de Anápolis (2014)

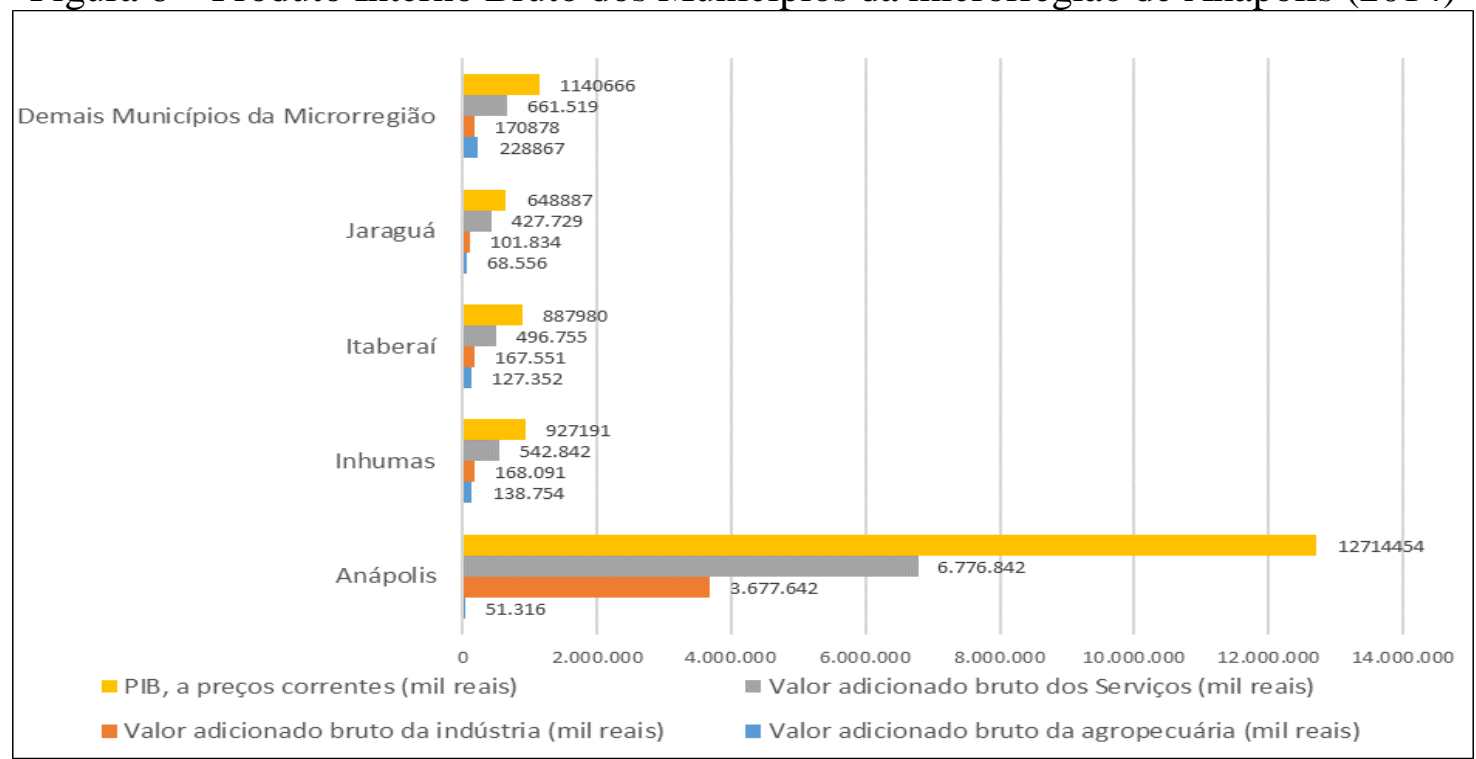

Fonte: IBGE, @cidades 2017, dados organizados pelos Autores.

Outros pontos que merecem destaque na análise dos dados do PIB 2014 (Figura 6), referem-se ao setor agropecuário, em que os municípios desse setor que exerceram maior influência no desempenho econômico foram: Inhumas e Itaberaí. Sendo Inhumas o município da microrregião onde a agropecuária tem o maior peso (R\$ 138.754 mil ou 22,57\% do valor Adicionado Bruto (VAB) ${ }^{2}$, ou seja, os 2 municípios juntos representam 43,28\% (R 266.106 mil) VAB do setor agropecuário na microrregião, seguidos por Jaraguá com $11,15 \%$ e Anápolis com 8,35\%. Nesse setor, os demais municípios da microrregião conseguem

\footnotetext{
${ }^{2}$ O Valor Adicionado Bruto (VAB) é o valor que cada setor da economia (agropecuária, indústria e serviços) acresce ao valor final de tudo que foi produzido em uma região. O Produto Interno Bruto (PIB) é a soma dos VABs setoriais e dos impostos, e é a principal medida do tamanho total de uma economia. (Fonte: http://atlas.fee.tche.br/rio-grande-do-sul/economia/pib-vab-do-rs/).
} 
RIBEIRO, I. S.; LUZ, J. S.; LUNAS, D. A. L.

A dinâmica agroindústrial na microrregião de Anápolis

demonstrar um valor percentual expressivo com 37,22\% do VAB agropecuário da microrregião.

Em relação ao segmento industrial, a cidade de Anápolis, em 2014, respondia sozinha por $85,81 \%(\mathrm{R} \$ 3.677 .642 \mathrm{mil})$ do VAB industrial da microrregião (Gráfico 2), seguida pelos municípios de Inhumas (3,92\%), Itaberaí (3,91\%) e Jaraguá (2,38\%). Assim, a soma do VAB industrial dos demais municípios da microrregião não passa de $\mathrm{R} \$ 170.878$ mil (3,99\% do total), o que demonstra a concentração industrial na cidade de Anápolis e nos subpolos da microrregião, em detrimento dos demais municípios da microrregião.

No que se refere ao $\mathrm{VAB}$ de serviços, segue a mesma dinâmica do VAB industrial, sendo Anápolis o município que mais se destaca nesse segmento, seguido por Inhumas, Itaberaí e Jaraguá. Nessa mesma dinâmica apresentada para o PIB, ao se observar a Figura 7, relativa ao número de estabelecimentos agroindustriais por microrregião, a microrregião de Goiânia se destaca com 33,26\% (468 estabelecimentos) das empresas selecionadas para representar o setor agroindustrial, seguida pela microrregião de Anápolis que é objeto desse estudo com 11,30\% (159 estabelecimentos). Enquanto, a microrregião Sudoeste de Goiás fica em terceiro lugar, com 9,74\% (137 estabelecimentos), o que demonstra a importância da microrregião aqui estudada para a agroindústria goiana.

Figura 7 - Estabelecimentos Agroindustriais por microrregião (Goiás)

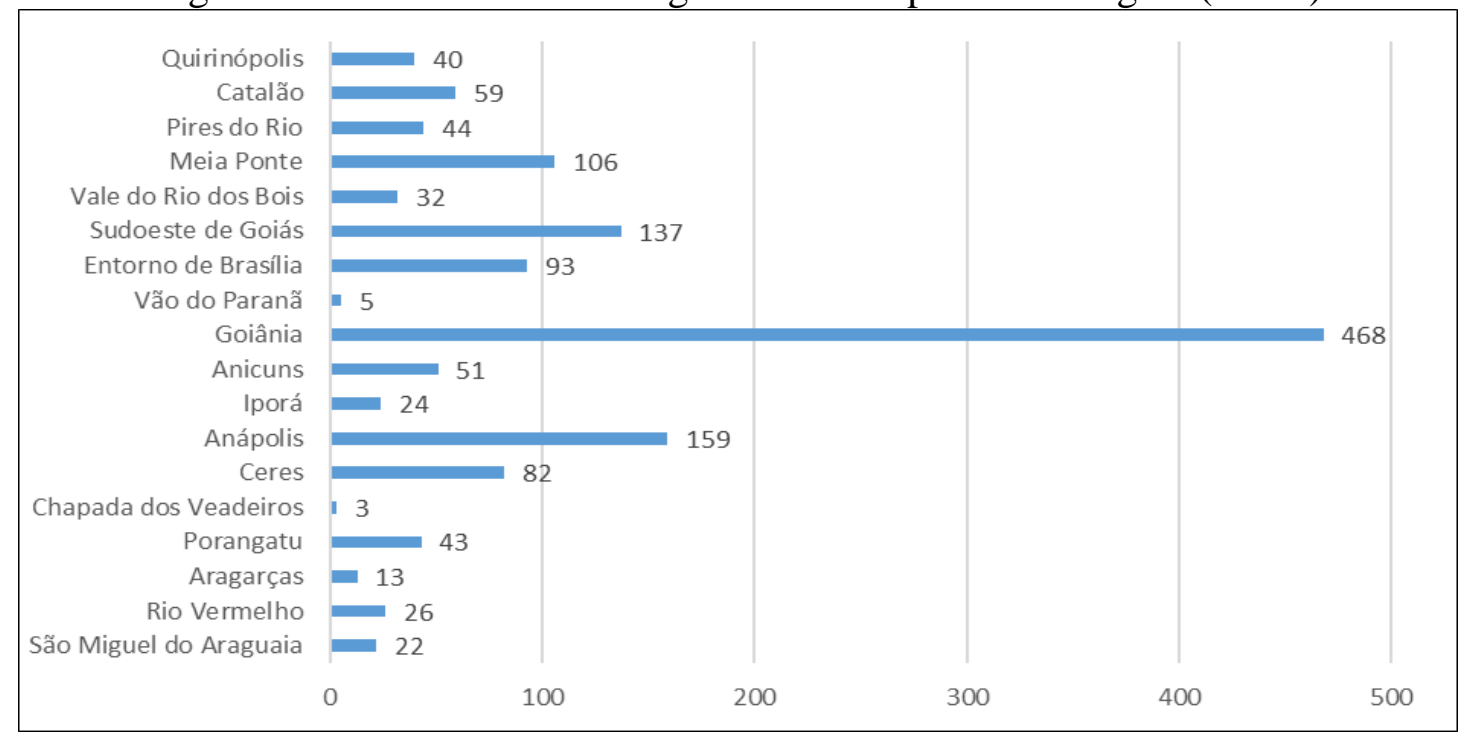

Fonte: Ministério do trabalho e Emprego (MTE/RAIS, 2015), dados organizados pelos Autores.

Conforme dados da Relação Anual de Informações Sociais (RAIS, 2014), a microrregião de Anápolis possui 159 estabelecimentos agroindustriais (Figura 7) que 
RIBEIRO, I. S.; LUZ, J. S.; LUNAS, D. A. L.

A dinâmica agroindústrial na microrregião de Anápolis

representam 11,30\% dos estabelecimentos agroindustriais do Estado, empregando 9.523 trabalhadores (RAIS, 2014). Porém, a distribuição dessas empresas na microrregião é bastante desigual, seguindo a mesma dinâmica do PIB industrial, conforme verifica-se na Figura 8.

Figura 8 - Estabelecimentos Agroindustriais na microrregião de Anápolis

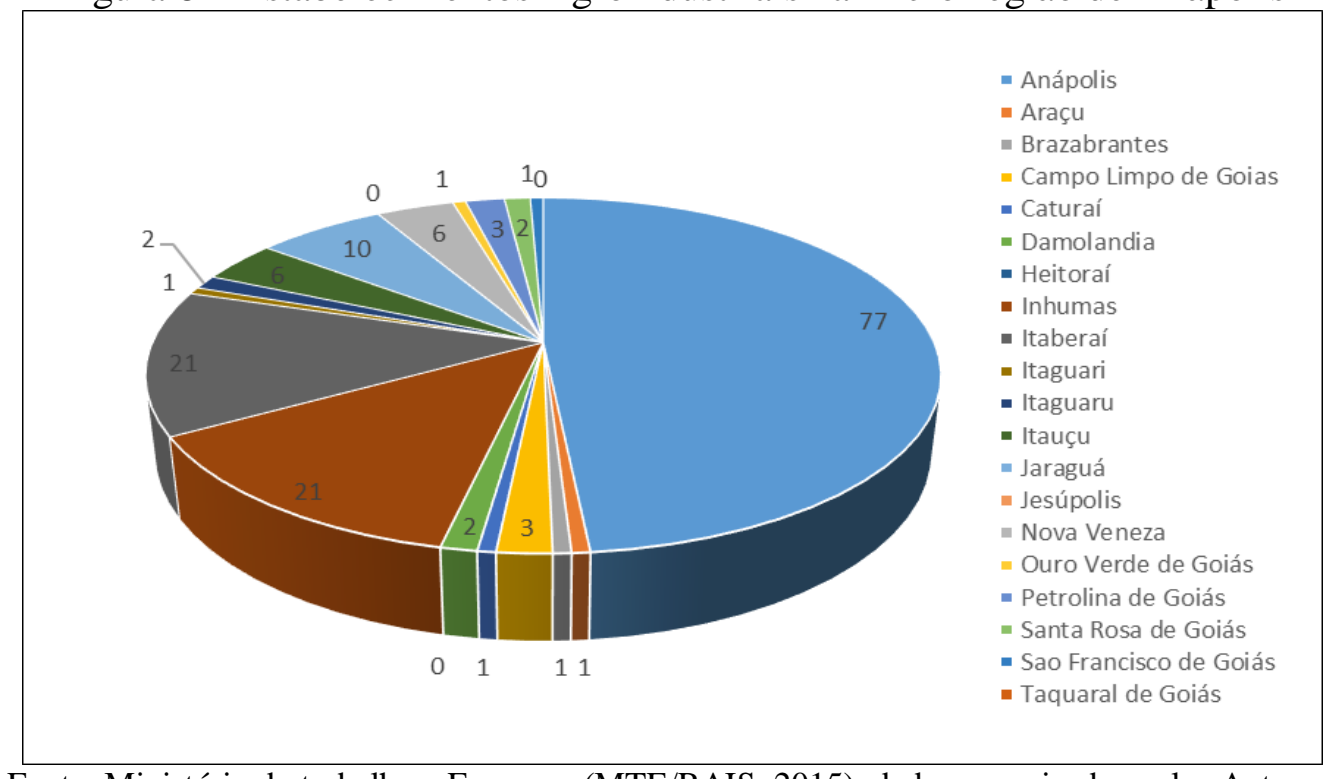

Fonte: Ministério do trabalho e Emprego (MTE/RAIS, 2015), dados organizados pelos Autores.

Pode-se evidenciar na Figura 8 que Anápolis concentra 48,43\% (77 empresas) das agroindústrias da microrregião, seguidas pelos municípios de Inhumas e Itaberaí (21 empresas cada), totalizando 26,40\% das empresas, enquanto Jaraguá conta com 10 estabelecimentos agroindustriais $(6,29 \%$ do total).

Tabela 1 - Estabelecimentos Agroindustriais na microrregião de Anápolis (2014)

\begin{tabular}{l|c|c|c|c|c|c|c}
\hline CNAE 2.0 Classe & Anápolis & Inhumas & Itaberaí & Jaraguá & $\begin{array}{l}\text { Demais } \\
\text { Municípios da } \\
\text { microrregião }\end{array}$ & $\begin{array}{l}\text { Total } \\
\text { microrregião }\end{array}$ & $\begin{array}{l}\text { Total } \\
\text { Goiás }\end{array}$ \\
\hline $\begin{array}{l}\text { Abate de Reses, Exceto } \\
\text { Suínos }\end{array}$ & 2 & 4 & 1 & 1 & 4 & 12 & 98 \\
\hline $\begin{array}{l}\text { Abate de Suínos, Aves e } \\
\text { Outros } \\
\text { Animais Pequenos }\end{array}$ & 4 & 1 & 4 & 0 & 3 & 12 & 68 \\
\hline $\begin{array}{l}\text { Fabricação de Produtos } \\
\text { de Carne }\end{array}$ & 6 & 2 & 1 & 0 & 2 & 11 & 99 \\
\hline $\begin{array}{l}\text { Preservação do Pescado } \\
\text { e Fabricação de Produtos } \\
\text { do Pescado }\end{array}$ & 0 & 0 & 0 & 0 & 1 & 1 & 8 \\
\hline $\begin{array}{l}\text { Fabricação de Conservas } \\
\text { de Frutas }\end{array}$ & 3 & 0 & 0 & 0 & 1 & 4 & 24 \\
\hline $\begin{array}{l}\text { Fabricação de Conservas } \\
\text { de Legumes e Outros } \\
\text { Vegetais }\end{array}$ & 4 & 0 & 0 & 0 & 2 & 6 & 24 \\
\hline Fabricação de Sucos de & 3 & 0 & 0 & 0 & 0 & 3 & 15 \\
\hline
\end{tabular}

Revista Cerrados, Montes Claros/MG, v. 16, n. 2, p. 89-109, jul./dez.-2018. 
RIBEIRO, I. S.; LUZ, J. S.; LUNAS, D. A. L.

Continuação da tabela 1

A dinâmica agroindústrial na microrregião de Anápolis

\begin{tabular}{|c|c|c|c|c|c|c|c|}
\hline $\begin{array}{l}\text { Frutas, Hortaliças } \mathrm{e} \\
\text { Legumes }\end{array}$ & & & & & & & \\
\hline $\begin{array}{l}\text { Fabricação de } \\
\text { Vegetais éleos } \\
\text { Exceto óleo de Milho }\end{array}$ & 1 & 0 & 0 & 0 & 0 & 1 & 42 \\
\hline $\begin{array}{ll}\text { Fabricação de óleos } \\
\text { Vegetais } & \text { Refinados, } \\
\text { Exceto óleo de Milho }\end{array}$ & 1 & 0 & 0 & 0 & 0 & 1 & 7 \\
\hline Preparação do Leite & 0 & 1 & 1 & 1 & 1 & 4 & 45 \\
\hline Fabricação de Laticínios & 3 & 1 & 2 & 2 & 14 & 22 & 179 \\
\hline $\begin{array}{l}\text { Beneficiamento de Arroz } \\
\text { e Fabricação de Produtos } \\
\text { do Arroz }\end{array}$ & 8 & 0 & 0 & 2 & 0 & 10 & 38 \\
\hline $\begin{array}{l}\text { Moagem de Trigo e } \\
\text { Fabricação de Derivados }\end{array}$ & 1 & 0 & 0 & 0 & 0 & 1 & 10 \\
\hline $\begin{array}{l}\text { Fabricação de Farinha de } \\
\text { Mandioca e Derivados }\end{array}$ & 0 & 0 & 1 & 0 & 0 & 1 & 22 \\
\hline $\begin{array}{l}\text { Fabricação de Farinha de } \\
\text { Milho e Derivados, } \\
\text { Exceto óleos de Milho }\end{array}$ & 2 & 3 & 0 & 0 & 0 & 5 & 24 \\
\hline $\begin{array}{l}\text { Fabricação de Alimentos } \\
\text { para Animais }\end{array}$ & 14 & 1 & 7 & 2 & 1 & 25 & 184 \\
\hline \begin{tabular}{lr}
\multicolumn{3}{l}{ Moagem e Fabricação de } \\
Produtos de Origem \\
Vegetal & não \\
Especificados & \\
Anteriormente & \\
\end{tabular} & 1 & 0 & 0 & 0 & 0 & 1 & 21 \\
\hline $\begin{array}{l}\text { Fabricação de Açúcar em } \\
\text { Bruto }\end{array}$ & 2 & 0 & 0 & 0 & 0 & 2 & 16 \\
\hline $\begin{array}{l}\text { Torrefação e Moagem de } \\
\text { Café }\end{array}$ & 3 & 3 & 1 & 0 & 0 & 7 & 56 \\
\hline $\begin{array}{lr}\text { Fabricação } & \text { de } \\
\text { Aguardentes e } \text { Outras } \\
\text { Bebidas Destiladas }\end{array}$ & 2 & 0 & 0 & 0 & 0 & 2 & 11 \\
\hline $\begin{array}{l}\text { Fabricação de Malte, } \\
\text { Cervejas e Chopes }\end{array}$ & 1 & 0 & 0 & 0 & 0 & 1 & 15 \\
\hline $\begin{array}{l}\text { Fabricação de Produtos } \\
\text { do Fumo }\end{array}$ & 1 & 0 & 0 & 0 & 0 & 1 & 4 \\
\hline $\begin{array}{l}\text { Curtimento e Outras } \\
\text { Preparações de Couro }\end{array}$ & 0 & 1 & 0 & 0 & 0 & 1 & 29 \\
\hline $\begin{array}{lr}\text { Fabricação de } & \text { Artefatos } \\
\text { de Couro } & \text { não } \\
\text { Especificados } & \\
\text { Anteriormente } & \\
\end{array}$ & 3 & 0 & 0 & 1 & 0 & 4 & 73 \\
\hline $\begin{array}{l}\text { Fabricação de Calçados } \\
\text { de Couro }\end{array}$ & 5 & 3 & 1 & 1 & 1 & 11 & 155 \\
\hline Fabricação de álcool & 1 & 1 & 0 & 0 & 0 & 2 & 33 \\
\hline $\begin{array}{l}\text { Fabricação de Adubos e } \\
\text { Fertilizantes }\end{array}$ & 5 & 0 & 1 & 0 & 0 & 6 & 51 \\
\hline $\begin{array}{lr}\text { Fabricação } & \text { de } \\
\text { Medicamentos para Uso } \\
\text { Veterinário }\end{array}$ & 1 & 0 & 0 & 0 & 0 & 1 & 10 \\
\hline $\begin{array}{l}\text { Fabricação de Máquinas } \\
\text { e Equipamentos para a } \\
\text { Agricultura e Pecuária, } \\
\text { Exceto para Irrigação }\end{array}$ & 0 & 0 & 1 & 0 & 0 & 1 & 46 \\
\hline TOTAIS & 77 & 21 & 21 & 10 & 30 & 159 & 1407 \\
\hline
\end{tabular}

Fonte: Ministério do trabalho e Emprego - MTE, RAIS 2015

* Classificação de Paranaíba (2012), Adaptada pelos Autore. 
RIBEIRO, I. S.; LUZ, J. S.; LUNAS, D. A. L.

A dinâmica agroindústrial na microrregião de Anápolis

Ao se analisar a Tabela 1 referente aos estabelecimentos industriais, o município de Anápolis se destaca nas atividades a montante ${ }^{3}$ do segmento agroindustrial, tais como: a fabricação de insumos para agropecuária com 14 empresas relacionadas à fabricação de alimentos para animais, 5 de adubos e fertilizantes; também para o beneficiamento de arroz, com 8 empresas, evidenciando a tradição cerealista do município e sua importância no desenvolvimento agroindustrial do estado. Por sua vez, os municípios de Inhumas e Itaberaí, apresentam também um grande número de empresas da cadeia do agronegócio, com destaque para o abate de reses, suínos e aves (5 empresas cada). Por fim, o município de Jaraguá se destaca na fabricação de laticínios, beneficiamento de arroz e alimentos para animais com 2 industrias em cada segmento.

Os demais municípios da microrregião juntos possuem apenas $25 \%$ das empresas selecionadas para o estudo, com destaque para as empresas relacionadas à cadeia do leite (14 empresas). Mas esses municípios apresentam alto grau de dependência das atividades primárias, por exemplo, a agropecuária, responsável por 9,76\% dos postos de trabalho ativos, contra 0,86\% em Anápolis, cidade com uma economia mais diversificada (Tabela 2). Esses municípios também apresentam atividades comerciais e de prestação de serviços, porém pouco desenvolvidos, são setores normalmente responsáveis pela maioria dos empregos formais. Empregam apenas 11,94\% e 11,58\% da população respectivamente, enquanto nos municípios polo esse percentual varia na casa de 17 a $22 \%$ para o comércio e de 13 a $32 \%$ para os serviços (tabela 2). Destaca-se, que nesses municípios menores, o grande responsável pelos empregos formais é o poder público (35\%).

Tabela 2 - Vínculos ativos por setor (IBGE) em percentual, para Municípios da microrregião de Anápolis (2015)

\begin{tabular}{l|c|c|c|c|c}
\hline IBGE SETOR & Anápolis & Inhumas & Itaberaí & Jaraguá & $\begin{array}{c}\text { Demais Municípios da } \\
\text { microrregião }\end{array}$ \\
\hline \begin{tabular}{l} 
1 - Extrativa mineral \\
\hline $\begin{array}{l}\text { - Indústria de } \\
\text { transformação }\end{array}$
\end{tabular} & $0,07 \%$ & $0,00 \%$ & $0,01 \%$ & $0,35 \%$ & $0,49 \%$ \\
\hline $\begin{array}{l}\text { 3 - Serviços industriais de } \\
\text { utilidade pública }\end{array}$ & $28,58 \%$ & $31,61 \%$ & $38,19 \%$ & $37,06 \%$ & $27,77 \%$ \\
\hline 4 - Construção Civil & $3,61 \%$ & $0,91 \%$ & $1,29 \%$ & $0,75 \%$ & $0,03 \%$ \\
\hline 5 - Comércio & $22,62 \%$ & $22,43 \%$ & $17,05 \%$ & $18,00 \%$ & $3,06 \%$ \\
\hline 6 - Serviços & $32,71 \%$ & $18,44 \%$ & $13,04 \%$ & $17,54 \%$ & $11,94 \%$ \\
\hline
\end{tabular}

\footnotetext{
${ }^{3}$ Considera-se aqui as atividades relativas a fabricação de adubos, fertilizantes, medicamentos para uso veterinário, bem como de máquinas e equipamentos.
} 
RIBEIRO, I. S.; LUZ, J. S.; LUNAS, D. A. L.

Continuação da tabela 2

A dinâmica agroindústrial na microrregião de Anápolis

\begin{tabular}{l|c|c|c|c|c}
\hline 7 - Administração Pública & $10,80 \%$ & $14,05 \%$ & $16,87 \%$ & $20,90 \%$ & $35,37 \%$ \\
\hline $\begin{array}{l}8 \text { - Agropecuária, extração } \\
\text { vegetal, caça e pesca }\end{array}$ & $0,86 \%$ & $12,52 \%$ & $13,51 \%$ & $5,15 \%$ & $9,76 \%$ \\
\hline Total & $100,00 \%$ & $100,00 \%$ & $100,00 \%$ & $100,00 \%$ & $100,00 \%$ \\
\hline
\end{tabular}

Fonte: Ministério do trabalho e Emprego (MTE/RAIS, 2015), dados organizados pelos Autores.

A falta de oportunidade de trabalho, nesses municípios, acarreta dentre outros fatores uma estagnação ou mesmo um decréscimo populacional, como é o caso dos Municípios de Araçu, Ouro Verde de Goiás e Santa Rosa de Goiás (conforme estimativa do IBGE entre 2014 e 2016 - Tabela 3), muito em função da migração da população jovem para centros maiores em busca de emprego.

Tabela 3 - População do Municípios da microrregião de Anápolis, 2014 e estimativa 2016

\begin{tabular}{|c|c|c|}
\hline Municípios da microrregião & População Censo 2014 & Estimativa Populacional 2016 \\
\hline Anápolis & 334.613 & 370.875 \\
\hline Araçu & 3.802 & 3.753 \\
\hline Brazabrantes & 3.232 & 3.565 \\
\hline Campo Limpo de Goiás & 6.241 & 7.219 \\
\hline Caturaí & 4.686 & 5.010 \\
\hline Damolândia & 2.747 & 2.919 \\
\hline Heitoraí & 3.571 & 3.774 \\
\hline Inhumas & 48.246 & 51.932 \\
\hline Itaberaí & 35.371 & 40.259 \\
\hline Itaguarí & 4.513 & 4.717 \\
\hline Itaguaru & 5.437 & 5.472 \\
\hline Itauçu & 8.575 & 8.998 \\
\hline Jaraguá & 41.870 & 47.513 \\
\hline Jesúpolis & 2.300 & 2.460 \\
\hline Nova Veneza & 8.129 & 9.249 \\
\hline Ouro Verde de Goiás & 4034 & 3.993 \\
\hline Petrolina de Goiás & 10283 & 10.548 \\
\hline Santa Rosa de Goiás & 2909 & 2.679 \\
\hline São Francisco de Goiás & 6120 & 6.354 \\
\hline Taquaral de Goiás & 3541 & 3.625 \\
\hline Total & 540.220 & 594.914 \\
\hline
\end{tabular}

Fonte: IBGE@Cidades 2017, dados organizados pelos Autores. 
RIBEIRO, I. S.; LUZ, J. S.; LUNAS, D. A. L.

A dinâmica agroindústrial na microrregião de Anápolis

Esse ciclo de falta de oportunidades: migração da população economicamente ativa e decréscimo populacional, acaba por contribuir para a manutenção da estagnação também no campo econômico, daí a necessidade de se desenvolver novas fontes de emprego e renda, como é o caso da cadeia agroindustrial, tema abordado nesse artigo.

\section{CONSIDERAÇÕES FINAIS}

O presente estudo teve como objetivo principal analisar a situação atual do ramo agroindustrial na microrregião de Anápolis por meio do estudo dos indicadores disponíveis. Como é possível verificar, a microrregião de Anápolis tem um papel relevante na formação do PIB do Estado, com um peso significativo em relação ao recorte Agroindustrial, ficando inclusive à frente de regiões famosas pela pujança de seu agronegócio, como é o caso do sudoeste Goiano.

Porém, ao analisar os dados da microrregião, observa-se uma excessiva concentração desses estabelecimentos em apenas 4 municípios (Anápolis, Inhumas, Itaberaí e Jaraguá), sendo que Anápolis, apesar de não ser uma cidade que se destaca na agropecuária, concentra grande parte das indústrias de insumos agropecuários, principalmente, em função do efeito polarizador de uma cidade industrial e centro regional. Enquanto em Inhumas e Itaberaí essa concentração é bastante ligada ao fato de serem municípios com grande produção agropecuária, já, no município de Jaraguá, apesar de menos relevante em relação aos três primeiros, essa concentração ocorre naturalmente em função da condição de subpolo, ficando os demais municípios à margem desse desenvolvimento.

Dessa forma, observa-se a necessidade de se instalar políticas públicas que objetivem distribuir melhor a atividade Agroindustrial entre os municípios, pois evidencia-se uma grande dependência do setor agrícola e da administração pública. Situação que revela a fragilidade econômica desses municípios, resultando em falta de opções de emprego para a população urbana.

Nesse sentido, uma opção seria fomentar a utilização, por parte dos pequenos agricultores, de linhas de crédito específicas para o setor, com vistas à implantação de pequenas atividades agroindustriais, tais como: laticínios, granjas, dentre outros. Como exemplo tem o caso do Pronaf-Agroindústria, linha de crédito específica para o financiamento 
RIBEIRO, I. S.; LUZ, J. S.; LUNAS, D. A. L.

A dinâmica agroindústrial na microrregião de Anápolis

de agroindústrias familiares, além de se poder investir em cursos de formação técnica e gerencial voltados para o empreendedorismo nas pequenas propriedades rurais.

Tais ações propiciariam meios para se agregar valor à produção agrícola dos pequenos municípios, contribuindo para o desenvolvimento econômico e a fixação da população economicamente ativa nos municípios menores, evitando a tendência de migração da população mais jovem para os grandes centros.

\section{REFERÊNCIAS}

ABAGRP, Associação Brasileira do Agronegócio da Região de Ribeirão Preto. Agronegócio - Conceito. Disponível em: http://www.abagrp.org.br/agronegocio Conceito.php. CASTRO, Ana Célia; Fonseca, Maria da Graça D. A dinâmica agroindustrial do centrooeste. Brasília: IPEA, 1995.

CASTRO, Mario Cesar Gomes de. Industrialização em Goiás: política industrial e desenvolvimento, 1970 a 2010. Tese (doutorado) - Universidade Federal do Rio de Janeiro, Instituto de Economia, Programa de Pós-Graduação em Políticas Públicas, Estratégias e Desenvolvimento, 2014. Disponível em: http://www.ie.ufrj.br/images/pos-graducao/pped/ dissertacoes_e_teses/MARIO_CESAR_GOMES_DE_CASTRO.pdf.

DELGADO, Guilherme. Capital financeiro e agricultura no Brasil. São Paulo, ICONE. Unicamp, 1985. $240 \mathrm{p}$.

FGV-EESP, Fundação Getúlio Vargas, Escola de Economia de SãoPaulo - Centro de Estudos do Agronegócios. Agronegócio representa $28 \%$ do PIB goiano (29/04/2014). Disponível em: http://gvagro.fgv.br/en/node/408.

GRAZIANO DA SILVA, José. A nova dinâmica da agricultura brasileira. $2^{\mathrm{a}}$ Ed. ver, Campinas, SP: UNICAMP. IE, 1998.

IBGE, Instituto Brasileiro de Geografia e Estatística. @Cidades. Disponível em: http://cidades.ibge.gov.br/xtras/home.php. Vários Acessos.

IBGE, Instituto Brasileiro de Geografia e Estatística. Censo 2010. Disponível em:http://censo2010.ibge.gov.br/.

IMB, Instituto Mauro borges. Concentração do PIB nas microrregiões de Goiás entre 2002 e 2011. Estudos do IMB. Outubro - 2014. Disponível em: www.imb.go. gov.br/estudos.asp.

IMB, Instituto Mauro borges. PIB - Produto Interno Bruto do Estado de Goiás, 20102014. Goiânia, IMB, novembro de 2016. Disponível em: <www.imb.go.gov.br/pub/pib /pib2014/pibgo2014.pdf>. Acesso em: 20/07/2017.

LUZ, Janes Socorro da. A (re) produção do espaço de Anápolis (go): A trajetória de uma cidade média entre duas metrópoles, 1970-2009. 2009. Tese (Doutorado em Geografia) - 
RIBEIRO, I. S.; LUZ, J. S.; LUNAS, D. A. L.

A dinâmica agroindústrial na microrregião de Anápolis

Universidade Federal de Uberlândia, Uberlândia: 2013. Disponível em http://www.bdtd.ufu.br/tde_busca/arquivo.php?codArquivo=2811.

PARANAÍBA, Adriano de Carvalho. Agroindustrialização e incentivos fiscais estaduais em Goiás. 2012. Dissertação (Mestrado em Agronegócio). Programa de Pós-graduação em Agronegócio da Universidade Federal de Goiás (PPAGRO). Disponível em: https://repositorio.bc.ufg.br/tede/handle/tde/419.

RAIS, Registro Anual de Informações Sociais. Bases Estatísticas RAIS e CAGED. Disponível em: http://bi.mte.gov.br/bgcaged/inicial.php.

SHIKI, Shigeo. Sistema agroalimentar nos cerrados brasileiros: caminhando para o caos. In: Shiki, S.; Silva, J.G. da; Ortega, A, C. Agricultura, Meio Ambiente e Sustentabilidade do cerrado Brasileiro. Uberlândia: UFU, 1997. P. 135-165.

SILVA, Júlia Bueno de Morais. O interior e sua importância no projeto centralizador do Brasil: Anápolis anos 20-30. Dissertação de Mestrado (Mestrado em História) Universidade Federal de Goiás - UFG, 1997. Disponível em: https://pos.historia.ufg.br/up /113/o/SILVA_J_lia_Bueno_de_Morais._1997.pdf.

\section{Autores}

Idelmar da Silva Ribeiro - Possui Graduação em Administração e Mestrado em Territórios e Expressões Culturais no Cerrado, ambos cursados pela Universidade Estadual de Goiás (UEG). Atualmente Trabalha na Secretaria da Fazenda do Estado de Goiás.

Janes Socorro da Luz - Possui Graduação em Geografia pela Universidade Estadual de Goiás (UEG), Mestrado em Geografia pela Universidade de Brasília (UnB) e Doutorado em Geografia pela Universidade Federal de Uberlândia (UFU). Atualmente é Professora do Programa de Pós-Graduação em Territórios e Expressões Culturais no Cerrado da Universidade Estadual de Goiás (UEG).

Divina Aparecida Leonel Lunas - Possui Graduação em Ciências Econômicas pela Fundação do Ensino Superior de Rio Verde (FESURV), Mestrado em Economia pela Universidade Federal de Uberlândia (UFU) e Doutorado em Desenvolvimento Econômico pela Universidade Estadual de Campinas (UNICAMP). Atualmente é Professora do Programa de Pós-Graduação em Territórios e Expressões Culturais no Cerrado da Universidade Estadual de Goiás (UEG).

Artigo recebido em: 28 de maio de 2018.

Artigo aceito em: 11 de julho de 2018.

Artigo publicado em: 12 de novembro de 2018 . 